\title{
EL VASO MAYA DE YALLOCH
}

\section{Por Marta Foncerrada de Molina}

Son muchos los ejemplos de vasijas pintadas mayas que muestran una alta calidad artística, tanto en su forma como en el diseño que los ornamenta. Entre éstos, existe un hermoso vaso maya hecho de barro rojo claro, decorado con dibujos en rojo sobre un fondo crema.

La forma del vaso es cilíndrica; tiene 26.8 centímetros de alto por 9.6 centímetros de base; esta última medida se estrecha en el borde superior, medio centímetro, acentuando con esto la esbelta simplicidad de la pieza.

El vaso aparece reproducido, a escala natural, en la lámina xvir del primer tomo de los tres que la Universidad de Pennsylvania publicó entre 1925 y $1943^{1}$ en los que se reunieron 48 ejemplares de vasijas mayas de gran valor artístico.

La lámina $x v_{I}$ de esta publicación muestra el grabado a colores del vaso cilíndrico tomado de una acuarela de Annie G. Hunter quien también dibujó en blanco y negro la superficie extendida del diseño decorativo, el que se reprodujo en la lámina xvir.

En la publicación de la Universidad de Pennsylvania se dice que el vaso procede de Honduras Británica y que pertenece a la colección del Museo de Bristol en Inglaterra. Sin embargo, 'Thomas Gann ${ }^{2}$ en 1918 relata que el vaso formó parte de una ofrenda funeraria depositada en un chultun (palabra maya que designa los depósitos artificiales excavados en la roca que se encuentran en gran número en los centros ceremoniales). El sitio donde se localizó este entierro es Yalloch en Guatemala, al otro lado de la frontera del distrito oeste de Honduras Británica y al noroeste del valle del río Mopan en el que se encuentran varias ciudades mayas periféricas como Benque Viejo, Ucanal e Ixkun cuyas estelas y altares poseen, según Thompson un estilo escultórico semejante al de la región del Petén. ${ }^{3}$

Gann dice que el chultun contenía numerosos fragmentos de fina cerámica decorada y dos vasos completos, uno de forma ovoide y otro

1 "Examples of Maya Pottery in the Museum and other Collections."

2 Gann, 1918, p. 138.

3 Thompson, 1931, p. 394. 
cilindrico $\sin$ fondo. Este último es el que le sirve de tema a este ensayo y el que Gann describe y reproduce en las láminas 26,27 y 28 de su libro.

Por otra parte, una nota en la publicación del Museo Peabody: "Las Ruinas de Holmul", aclara que el vaso no se encuentra en el Museo de Bristol como lo atestigua el Catálogo de la Universidad de Pennsylvania sino que pertenece a la colección de Arte Maya del Museo del American Indian, Heye Foundation de Nueva York.

La forma cilíndrica del vaso y la elaborada sofisticación de la escena que lo decora coloca esta pieza dentro del Clásico Tardio Maya (ca 600900 d.C.) en la fase correspondiente a la Tepeu de Uaxactun.

La escena decorativa incluye la representación de varias figuras humanas de pie, imágenes zoomorfas, símbolos religiosos y jeroglíficos.

La composición está dividida en dos grandes áreas de acuerdo con las dos mitades convexas que forman el volumen cilíndrico de la pieza; cada área pictórica tiene, respectivamente, como tema principal uno de los dos personajes de pie en posición frontal y uno de los dos pájaros de cuerpo serpentino, alrededor de los que se organizaron las otras dos figuras humanas y los elementos simbólicos y decorativos de la composición.

La escena está enmarcada en sus límites superior e inferior por una banda horizontal que encierra jeroglíficos. Entre estas dos bandas de jeroglíficos se desarrolla el tema central de la composición en el que se advierten dos zonas: una superior y otra inferior divididas por un eje horizontal ideal que pasa por encima de la cabeza de las figuras humanas de pie dibujadas en posición frontal.

La combinación de los ejes horizontales y verticales que idealmente enmarcan los diferentes elementos que constituyen la decoración de este vaso muestran, tanto en la zona superior como en la inferior, que la división del espacio pictórico se hizo por medio de rectángulos, los que el artista maya utilizó para distribuir y equilibrar armónicamente las formas que entran en la composición.

La zona inferior es, sin duda, la más importante ya que ocupa las dos terceras partes de la altura total del vaso y contiene el mayor número de elementos figurativos y simbólicos; entre los primeros, destacan los estupendos dibujos de los dos personajes de altivo porte y rico atavio que presiden la escena ceremonial.

La zona superior contiene un número menor de elementos; el espacio pictórico está dividido idealmente por cuatro rectángulos; de éstos el 
segundo y el cuarto están ocupados, respectivamente, por un pajaro representado de perfil, cuyo plumaje se alarga y se transforma en la silueta de un cuerpo serpentino que se curva hasta casi caer sobre el pico del ave. El pájaro que ocupa el rectángulo dos posiblemente representa un buitre, el largo pico tiene al centro y en la parte superior la característica protuberancia con que éste aparece dibujado en los códices mayas. Un adorno de concha decora la cabeza del ave cuyas plumas aparecen atadas hacia arriba en la parte posterior.

La cabeza del pájaro serpentino del rectángulo cuatro es un mascarón con mandíbula inferior descarnada, nariz decorada por un hueso y orejera de tres elementos; un bonete con plumas en la parte posterior corona este rostro mítico.

Los otros dos rectángulos de la zona superior, el uno y el tres contienen los ondulantes diseños que rematan el tocado de las dos importantes figuras humanas de la zona superior y los extendidos y ricamente decorados apéndices nasales de dos mascarones que se proyectan del cuerpo serpentino de cada uno de los pájaros y de los que pende un escudo. En el extremo del mascarón narigudo que ocupa la sección superior del rectángulo uno, se dibujó una extraña y grotesca cara barbada de difícil identificación iconográfica; de ésta cuelga, hacia abajo, un haz de cinco plumas. En el rectángulo dos, este remate consiste en un diseño de bandas entretejidas tipo estera del que sale otro haz de plumas.

El análisis de la composición del diseño extendido muestra que el espacio pictórico de la zona inferior fue dividido por una doble serie de seis rectángulos paralelos, formados por un eje horizontal o transverso y por la sucesión de los ejes verticales que estructuran los dibujos de las dos figuras humanas principales y los dos pedestales rematados respectivamente por el mascarón del dios narigudo el que, a su vez, le sirve de trono a una imágen zoomorfa a la que enmarca una banda celeste sobre la que descansan los dos pájaros míticos de la zona superior, descrita en el párrafo anterior.

Los ejes verticales de la zona inferior se han numerado del uno al seis sucesivamente a partir de la línea que idealmente divide en dos el cartucho de jeroglificos y el enano dibujado bajo éste.

A partir de la línea horizontal inferior sobre la que descansan las figuras humanas y los pedestales de la zona inferior, las letras A B y B C señalan los tres ejes transversales principales sobre los que se extiende la composición de la zona inferior.

Los ejes 2 y 5 señalan la situación dentro de la escena decorativa de 
las dos figuras humanas principales. Estas están representadas en posición frontal con el rostro de perfil; los pies abiertos hacia afuera formando un ángulo de $180^{\circ}$; los brazos de cada figura ligeramente flexionados se extienden a los lados, las rodillas suavemente flexionadas y los pies firmemente apoyados en el suelo muestran un dibujo que pareciera registrar la posición de dos cuerpos humanos captados en el instante en que va a iniciarse o concluye la secuencia de movimientos de una danza ritual.

El rostro de perfil del personaje sobre el eje 2 muestra las expresivas y enérgicas líneas de unos labios que se abren desmesuradamente con el gesto de un grito. Un pequeño diseño floral dibujado como si flotara en el espacio pictórico, a corta distancia del labio superior de la figura, pareciera fungir como simbolo de la palabra cantada y sugerir que el personaje está representado entonando un cántico o invocando los poderes divinos.

Otro diseño semejante, está próximo al rostro de perfil de la figura dibujada sobre el eje 5, la que, sin embargo, tiene los labios cerrados. A mi juicio estos símbolos de la palabra cantada parecen indicar que todos los personajes de esta escena participan en una ceremonia religiosa cuyo ritual incluye el canto y la danza.

En el eje 1, bajo el cartucho que encierra ocho jeroglíficos, un enano de regordete cuerpo levanta la cabeza hacia la figura arriba descrita, dos delgadas y pequeñas líneas salen de su boca y parecen indicar que está en comunicación verbal con ésta. El brazo izquierdo levantado hacia arriba y la mano larga y elegantemente extendida apuntan hacia el personaje de pie. El otro brazo flexionado sobre el cuerpo deja caer la mano hacia abajo. A pesar de lo grotesco de la figura, el movimiento de los brazos y las posiciones de las manos finamente dibujadas, crea una refinada curva que, plásticamente, resulta acertada dentro de la composición.

En los ejes 3 y 6 se levantan los pedestales rectangulares divididos en su parte central en varias secciones más o menos regulares. Del costado derecho del pedestal se desprenden pequeñas y ondulantes decoraciones flamígeras. El pedestal se abre ligeramente en la base, la que está formada por huesos y plumas.

En la parte superior del pedestal dibujado sobre el eje 3 se apoya un mascarón sin mandíbula inferior, con larga nariz que se levanta hacia arriba. El borde inferior de la mandíbula superior está limitado por varios dientes aserrados. El dibujo del mascarón sobre el eje 6 está 
muy deteriorado, pero aún puede apreciarse que el diseño fue muy semejante al del eje 3; se distingue de éste porque el extremo superior de la nariz que se curva hacia arriba remata en la cabeza de una serpiente de alargadas fauces entreabiertas que dejan ver los dientes aserrados; de la mandíbula inferior pende un haz de plumas que corre paralelo al cartucho de jeroglíficos.

Un diseño de plumas o de plumas y ramas constituido por la sucesión de pequeñas líneas horizontales paralelas, limitadas en la parte superior por ondulante borde de plumas, parece desprenderse de la parte posterior del mascarón y formar un rico marco que relaciona a las figuras humanas con la imagen religiosa, dejando un tanto impreciso, si se trata del penacho que las adornó o si es la representación de una mampara hecha de los materiales ya mencionados.

Bajo el dibujo de cintas trenzadas que flanquean las orejeras de los dos mascarones del dios de nariz larga caen paralelos al pedestal unos adornos formados por cuentas, listones y huesos.

La cabeza del mascarón constituye un trono sobre el que descansa una curiosa figura zoomorfa, más clara la del eje 3, casi borrada la del eje 6 pero indudablemente semejantes las dos.

La piel decorada con manchas del zoomorfo del eje 3 sugiere que se trata de un tigre; de su garra extendida pende una cabeza humana dibujada boca arriba, la que recibe y sostiene en la mano derecha la figura humana del eje 5; dos cintas cuelgan de esta cabeza humana, bajo ellas se dibujó la figura de un muchachito cuyo rostro de perfil y cabeza no parecen ser los de un maya y el que absorto, con las manos atadas a la espalda contempla la figura del personaje del eje 5 .

Las bandas celestes que forman el límite superior del marco que encierra las, dos representaciones de tigres, terminan al frente en cabezas de serpiente; la serpiente celeste que corresponde al pedestal sobre el eje 3 no tiene mandíbula superior, la del eje 6 sí se dibujó con mandíbula inferior y con pequeña y ondulante barba.

El tocado de la figura 2 es un casco que se ciñe al cráneó y cubre la frente; posiblemente este tipo de tocado no muy usual en el atavio maya se hacía de cuero, un material flexible a la vez que resistente. El casco está adornado en la parte superior por una serie de elementos superpuestos que se mueven ondulantes hasta la zona superior; entre éstos se advierten plumas, un mascarón de nariz roma y huesos atados con cintas; termina este rico ornamento con lo que pareciera ser un pequeño dragón al que remata largo y elegante haz de plumas que cae hacia 
abajo. Esta curiosa figurita se asemeja a otras que aparecen en la icono grafía palencana. El casco se alarga en la parte anterior y adquiere la forma de un mascarón de extendido apéndice nasal y sin mandíbula inferior. La sección lateral del rostro está cubierto por un adorno textil con trenzado de estera que oculta la orejera de la que sólo asoma parte de una cuenta redonda. El adorno textil posiblemente formó parte de la decoración posterior del casco.

La cabeza de perfil de la figura sobre el eje 5 está también cubierta por un casco cuyo dibujo es más claro y de más precisión que el de la figura 2. Se diferencia de este último por tener visera y atarse con un barbiquejo. Una banda que remata al frente en un mascarón de larga nariz, atraviesa el casco por encima de la visera; este elemento no rompe sino que acentúa la continuidad y fluidez de la línea que va de la nariz hasta la parte superior de la cabeza y muestra claramente la típica deformación craneana maya. Estos elementos junto con la fina línea que le da forma a los delgados labios y al enérgico mentón crean un perfil que posee la expresión de fuerza, arrogancia y dignidad de un guerrero victorioso.

Un mechón de plumas decora la parte superior del casco que ciñe la cabeza de esta figura; de las plumas surge un mascarón descarnado de larga nariz y sobre éste se suceden hacia arriba cintas tejidas, pequeños lazos y cuentas, hasta terminar en lo que pareciera una cabeza serpentina de abiertas fauces de cuyo interior brota un haz de plumas. El rico adorno superior del tocado de la figura 2 invade casi todo el espacio comprendido entre los dos pájaros de cuerpo serpentino de la zona superior. El personaje se adorna con orejera alargada de hueso con cortes aserrados semicirculares y a la que atraviesa en su parte inferior otro hueso. Los dos personajes portan como accesorios ornamentales, collares rematados por un medallón en forma de rosetón del que penden otros adornos circulares. Es curioso notar que el artista distorsionó la realidad visual al dibujar sobre el alargado cuello de la figura del eje 5, el remate posterior del collar.

Destaca en el atuendo de las dos figuras principales el cinturón compuesto por tres elementos: medallón ovalado al centro, cruzado en su parte media por un lazo o atadura, una sección cuadrada decorada con dos bandas cruzadas en forma de $\mathrm{X}$ y un remate de voluta en los costados; en la parte superior del cuadrado decorado con cruz se insertó un hueso. Bajo esta sección del cinturón como parte de éste o tal vez del 
máxtlatl * se proyecta del costado derecho de ambas figuras, un gran mascarón descarnado, de larga nariz decorada con huesos.

El lazo central del máxtlatl se prolonga por entre las piernas abiertas de los dos personajes; una serie de adornos se encadenan entre sí hasta casi tocar el suelo; el diseño de esta sucesión de elementos hace más clara la estructura axial de cada figura. El eje central, sin embargo, no es perfectamente vertical sino que se inclina, sobre todo en la figura 2, lo que enfatiza el carácter dinámico y la expresividad de este personaje que grita o que canta. El máxtlatl consiste de varios elementos; en la parte superior se aprecia una forma oval semejante a la del cinturón aunque más pequeña que ésta; bajo ella cuelgan trozos de tela que se pliegan o se trenzan y cuentas de jade. El remate inferior consiste en una flor, posiblemente un lirio en el máxtlatl de la figura del eje 2 y en el de la figura del eje 5 , dos huesos cuyos extremos apuntan en direcciones divergentes.

Una serie de adornos de mascarones, cuentas de jade, caracoles, huesos y flores cuelgan a los lados del cinturón y caen hasta tocar las puntas de los pies de ambos personajes. Las dos figuras usan puños de cuentas y barras y se calzan con sandalias de talón descubierto y banda que une el cubretobillo con la suela. Las largas piernas del personaje del eje 5 están cubiertas con medias que le llegan hasta la rodilla.

El sistema de proporciones que rige a las cuatro figuras humanas que participan en la escena es de 6 cabezas para la figura dibujada sobre el eje 2; de una y media cabeza para la que ocupa el eje 5; de poco más de 3 cabezas son las proporciones del muchachito semidesnudo que observa a este último personaje y de $11 / 4$ cabezas aproximadamente, para la figura del enano. Las distintas proporciones de estas figuras y la flexibilidad de sus movimientos corporales contribuye a imprimirle a la composición un sentido dinámico.

El espíritu "barroco" maya se hace patente aun en una composición que, como ésta, es de pequeño formato. La regularidad geométrica y la simétrica organización del espacio pictórico dividido en rectángulos supo enriquecerlo el artista con el variado juego de líneas ondulantes y de ejes diagonales que constituyen los numerosos simbolos religiosos y ornamentales, así como el movimiento elíptico que crean los haces de plumas y los cuerpos serpentinos de los pájaros míticos de la zona superior de la composición. Un ritmo de formas asimétricas claramente equilibradas controla el diseño artístico en el que se presenta, como es tan frecuente

- Vocablo nahuatl. En maya se denomina Ek. 
en la plástica maya, a la figura humana rodeada por símbolos religiosos y signos jeroglíficos.

Sin pretender establecer una estricta relación de similitud con el desarrollo estilístico de la escultura maya del periodo clásico, según lo plantea Tatiana Proskouriakoff en su extraordinario estudio sobre esta manifestación del arte maya, considero que, tentativamente podría situarse el estilo pictórico del vaso, en el periodo correspondiente a la fase dinámica de la escultura maya del clásico tardío, la que la investigadora sitúa entre 9.16.0.0.0 y 9.19.0.0.0 (751-810 D.C.) alguna de cuyas características sintetizo aquí: "Posturas asimétricas. Roleos o volutas que frecuentemente se voltean sobre sí mismos. Haces de plumas repartidos en diferentes áreas las que dirigen el ojo hacia un área significativa dentro del diseño general. El énfasis que el artista pone en las cualidades dinámicas frecuentemente da por resultado una línea cursiva; composiciones estáticas continúan en uso pero puede observarse en ellas exageración en las formas para adaptarse al esquema general de la composición." 4 En la decoración del vaso, el movimiento asimétrico de brazos y manos, la inclinación del eje central que rige a las figuras en posición frontal, la cabeza de perfil del personaje dibujado con la boca desmesuradamente abierta cuya barba cubre el hombro derecho, las cabezas que se voltean hacia arriba, tanto del enano como del muchacho, parecen indicar que las posturas de los cuatro personajes representados en el vaso se ajustan a las características de asimetría y movimiento que Tatiana Proskouriakoff señala para el periodo dinámico de la escultura maya.

En el vaso se observa también que varias de las plumas se voltean sobre sí mismas y que los numerosos haces de plumas repartidos en el espacio pictórico dirigen el ojo hacia las formas figurativas y simbólicas más significativas de la composición, o sea que su papel dentro de ésta no es puramente decorativo sino forma parte del ritmo formal; cumplen una función plástica deliberadamente planeada por el artista.

El gusto por la línea cursiva que gira incesante para darle límite y medida a los numerosos y fantasiosos elementos simbólicos y ornamentales muestran en la decoración del vaso, como en la escultura del periodo dinámico, la preocupación de los artistas por los valores inherentes a la forma misma en cuanto diseño y al papel que ésta juega dentro de los grandes ejes direccionales de la composición.

4 Proskouriakoff, 1950, pp. 138-139. 
El sentido o significado simbólico contenido en la decoración del vaso de Yalloch, tal vez, represente el ritual que los mayas celebraban durante los cinco días ominosos conocidos como uayeb con que terminaba el año de 365 días y en los que se llevaban a cabo distintas ceremonias según el día, Kan, Ix, Muluc o Cauac con que fuera a iniciarse el año nuevo.

Los datos que se conocen sobre estas festividades provienen de la obra escrita en el siglo xvi por fray Diego de Landa. Con la natural reserva con que debe interpretarse el contenido social o religioso de cualquiera de las representaciones escultóricas o pictóricas mayas a la luz de los datos que sobre la cultura de Yucatán pudo recoger el obispo Landa, considero que el método es válido ya que su obra constituye una importante fuente documental y aunque tardía, ha sido necesario siempre recurrir a ella para intentar penetrar en el misterioso y complejo mundo mágico-religioso de los mayas del periodo clásico.

La escena del vaso de Yalloch parece representar una síntesis del ritual de los uayeb el que estuvo dedicado en general a los bacabs o dioses que sustentaban el cielo. Landa dice a este respecto lo siguiente:

Para celebrar la solemnidad del año nuevo, esta gente, con más regocijo y más dignamente, según su desventurada opinión, tomaba los cinco días aciagos que ellos tenían por tales antes del día primero de su nuevo año y en ellos hacian muy grandes servicios a los bacabes. 5 ... ponen a cada uno de estos (bacabes) otros nombres y señálanle con ellos a la parte del mundo que dios le tenía puesto deteniendo el cielo y aprópianle una de las cuatro letras dominicales a él y a la parte en que está; y tienen señaladas las miserias o felices sucesos que decían habían de suceder en el año de cada uno de éstos y de las letras con ellos. 6

La hipótesis de que la escena del vaso de Yalloch parece mostrar simultáneamente varios de los símbolos religiosos y de los seres y objetos que formaban parte del ritual de los uayeb o cinco días aciagos con que terminaba el año se basa en que algunas de las imágenes representadas en éste corresponden a lo que Landa cuenta sobre las festividades de los días aciagos y los del año nuevo, tanto en los días Kan como Muluc, Ix o Cauac con que éste podía empezar.

A continuación presento una lista de los elementos figurativos y sim-

6 Landa, 1938, p. 147.

- Nota: letras dominicales; asi nombra Landa los días en que podía empezar cada año nuevo: Kan, Ix, Muluc, Canac.

6 Landa, 1938, p. 146. 
bólicos que aparecen representados en el vaso y que parecen tener conexión con las festividades arriba mencionadas.

Figura humana de elevada estatura dibujada sobre el eje 5: en el ritual de todas las fiestas de los días aciagos se menciona a un príncipe del pueblo o principal encargado de guardar en su casa la imagen del dios venerado en esos días: "Elegían un príncipe del pueblo, en cuya casa se celebrara estos dias la fiesta, y para celebrarla hacian una estatua de un demonio..."7

La postura de los dos personajes principales del vaso que sugiere actitudes de danza y posiblemente, de canto, pudiera referirse a los bailes que se llevaban a cabo en estas festividades frente a las imágenes religiosas, tanto cuando una de éstas era trasladada desde las afueras del pueblo, como cuando se le colocaba frente a la imagen que guardaba en su casa el señor principal: “... y así la llevaban con mucho regocijo y bailes a la casa del principal donde estaba la otra estatua ..." 8 Esta referencia de Landa explicaría también la presencia en la escena decorativa de los pedestales que sostienen, respectivamente, un mascarón divino.

Los mascarones del dios narigudo que rematan los dos pedestales, los que se proyectan de la sección superior del cuerpo emplumado de las aves y los que decoran el atavio de los dos personajes principales, posiblemente, sean representaciones de Bolon Tz'acab, deidad venerada, según Landa, durante los años iniciados en el día Kan. Bolon Tz'acab, no parece ser sino una advocación más del dios de la lluvia cuya acción benéfica o malévola afectaba directamente la vida de los campos cultivados, de ahí que fuera una de las deidades que los mayas veneraron con mayor devoción. Landa nos dice: "... metían la imagen (de Bolon Tz'acab) en un palo llamado kanté; poniéndole a cuestas un ángel en señal de agua, y este año había de ser bueno y estos ángeles pintaban y hacían espantables". ${ }^{\circ}$

Las serpientes que rematan la banda celeste que enmarca a los dos tigres y la serpiente en que se transforma la alargada nariz del mascarón sobre el eje 6, parecen ser representación de Itzamná deidad que habita en el cielo también relacionada con el agua, concebida por los mayas como un ser fantástico con características ofideas y de cocodrilo y la que posiblemente Landa describe como "un ángel en señal de agua"

\footnotetext{
7 Landa, 1938, pp. 144, 145.

8 Landa, 1938, p. 148.

Ibidem, pp. 147-148.
} 
DOI: http://dx.doi.org/10.22201/iie.18703062e.1968.37.865

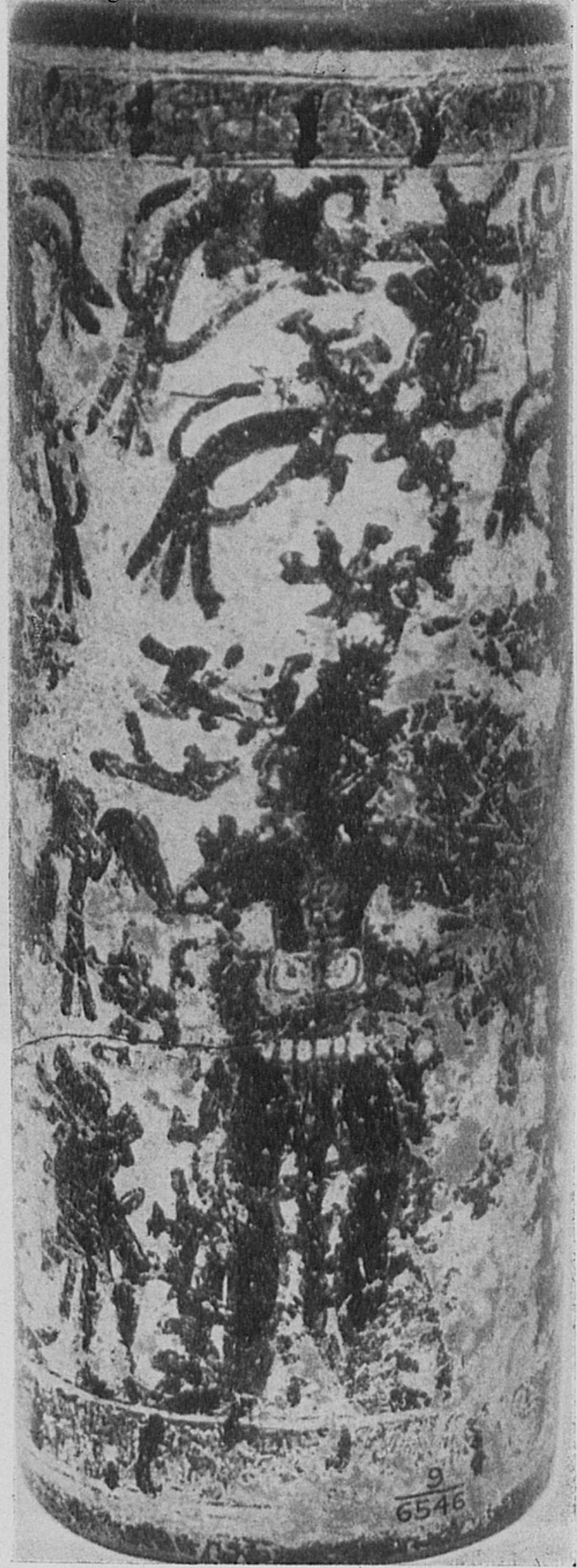

1. Vaso de Yalloch. Museum of the American Indian. New York 
DOI: http://dx.doi.org/10.22201/iie.18703062e.1968.37.865

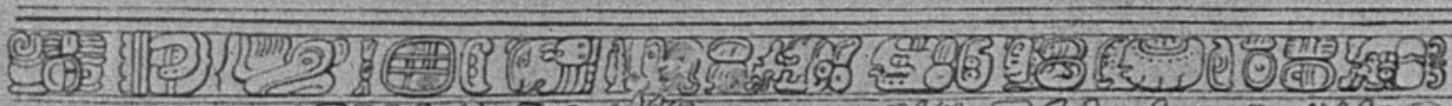

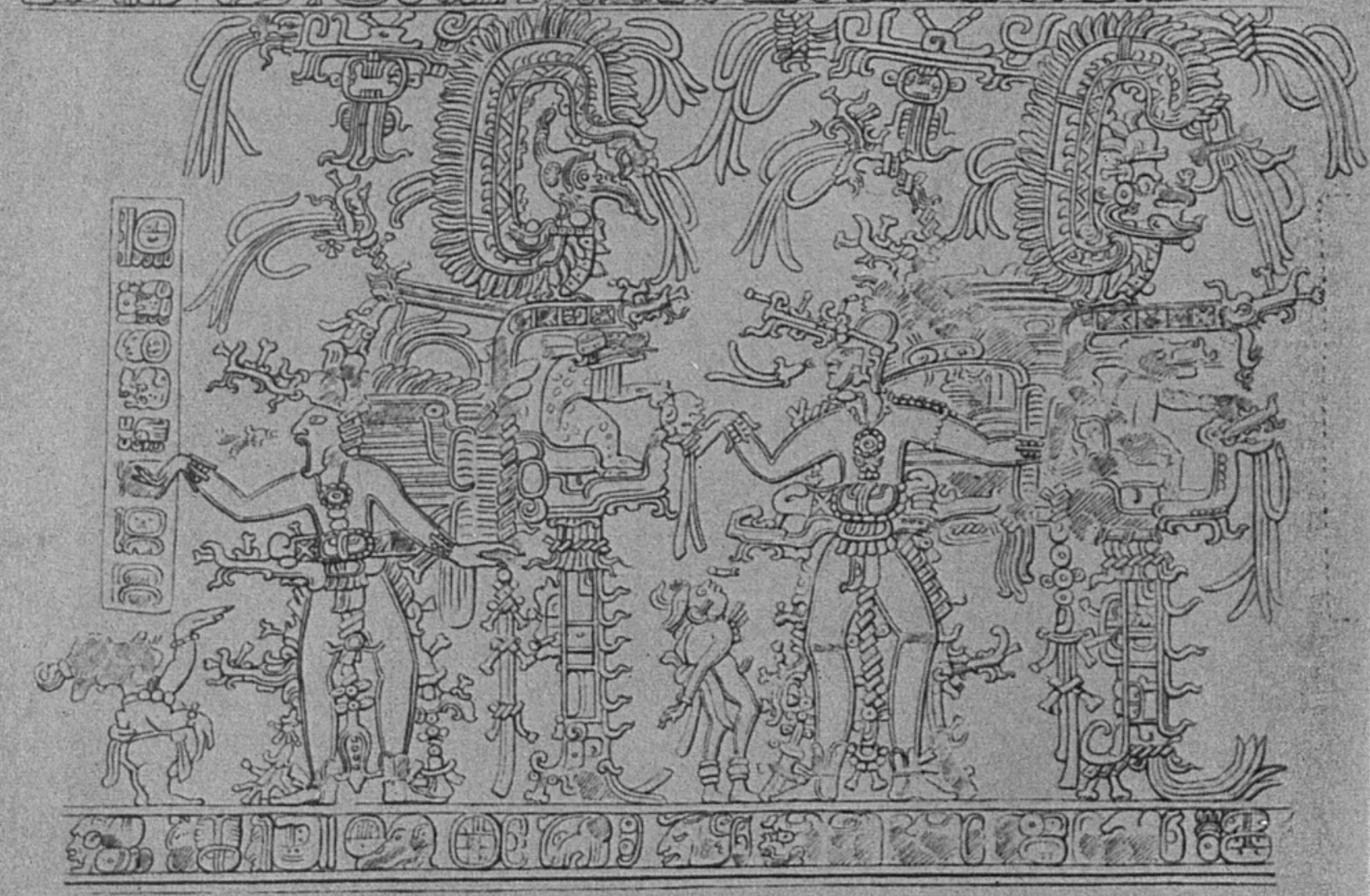

2. Desarrollo de la composición del vaso de Yalloch. Dibujo de Annie G. Hunter 
DOI: http://dx.doi.org/10.22201/iie.18703062e.1968.37.865

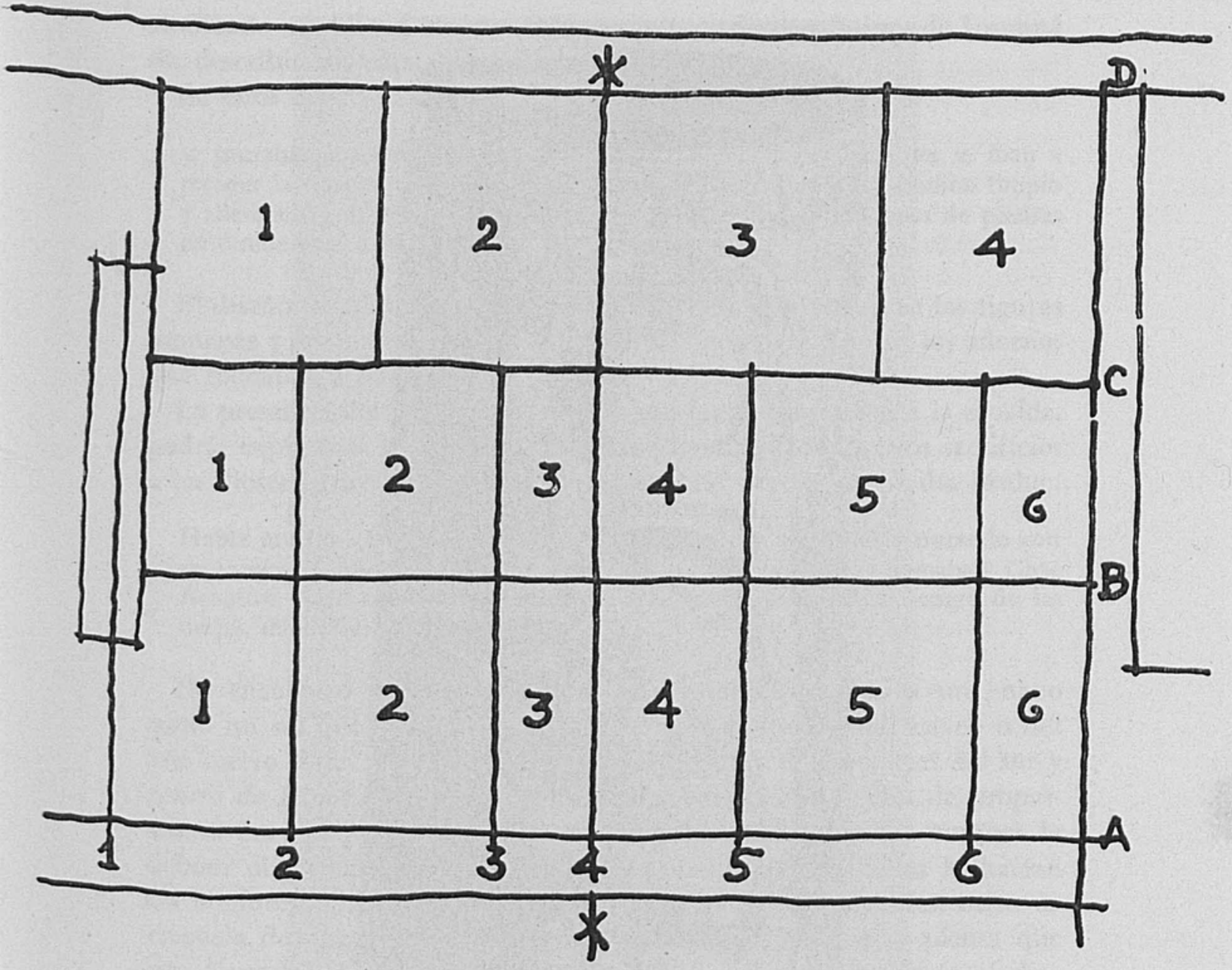

3. Esquema de la composición del vaso de Yalloch 
DOI: http://dx.doi.org/10.22201/iie.18703062e.1968.37.865

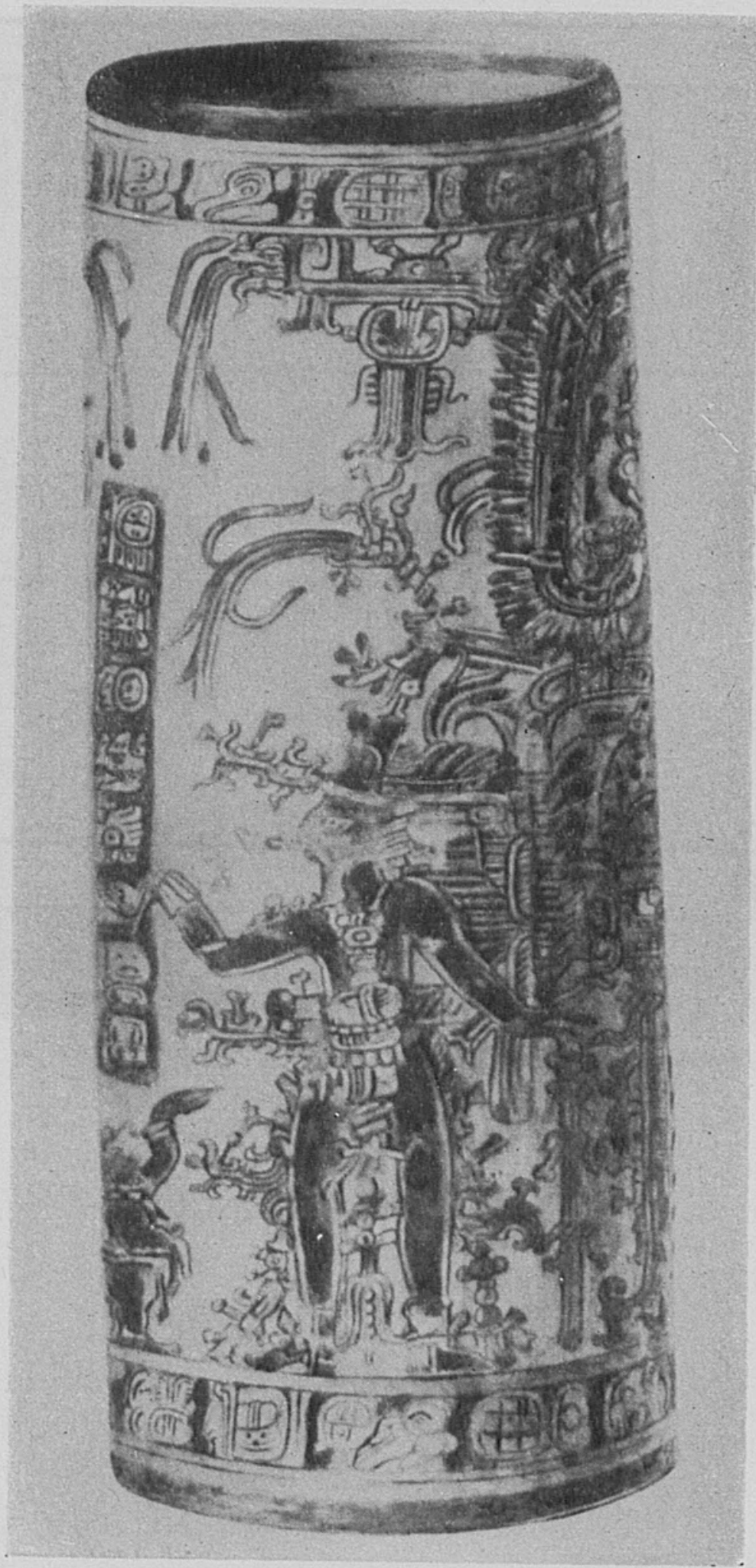

4. Vaso de Yalloch. Acuarela de Annie G. Hunter 
aludiendo con ello al carácter celeste y a los atributos divinos de Itzamná sin describir sus características iconográficas.

En estos dias:

se juntaban los señores y sacerdotes, y el pueblo de los hombres se iban a recoger la imagen del dios en las afueras del pueblo por un camino limpio y aderezado con arcos y frescuras hasta el lugar de los montones de piedras en donde estaba la estatua. 10

El diseño de plumas y ramas que en el vaso, aparece entre las figuras humanas y los mascarones divinos, posiblemente constituyan los adornos que rodeaban a las imágenes divinas.

La presencia del joven semidesnudo con las manos atadas a la espalda, podrfa explicarse de acuerdo con lo que Landa dice sobre los sacrificios a los dioses en los días anteriores al comienzo del año en el día Muluc:

Habia muchos que derramaban sangre, cortándose las orejas y untando con su sangre la piedra que alli tenian de un demonio que llamaban Chac Acantun. Aquí tomaban muchachos y por fuerza les sacaban sangre de las orejas, dándoles cuchilladas en ellas. 11

No encuentro en el relato de Landa ninguna alusión a un enano como un ser que participara en las ceremonias de los días uayeb o del año nuevo. Eric Thompson en su obra Etnologia de los mayas del sur y centro de Honduras Británicas de 1930, se refiere a un dios de proporciones muy pequeñas, Ah Tup a quien los señores de los bosques le debian obediencia y le entregaban las ofrendas que a ellos le hacian los hombres. Thompson añade que, entre los ladinos actuales, existe la creencia de que un enano inofensivo habita los bosques y piensa que esta leyenda tal vez, tenga su origen en el antiguo culto maya al dios Ah Tup. ${ }^{12}$ Como Yalloch, el sitio de Guatemala de donde procede el vaso colinda con Honduras Británicas, el enano podría representar en este caso, la inclusión de una divinidad local relacionada con los dioses terrestres. No es infrecuente, por otra parte, la presencia de enanos en la plástica maya; éstos aparecen en algunas estelas y en el famoso pectoral de jade procedente de Nebaj en los que, tal vez, representen, como en el arte occidental, bufones y éste sea el papel que juegue el enano en la escena ceremonial del vaso de Yalloch.

Es, a mi juicio, el ritual que precedía al año nuevo en el día Cauac

10 Landa, 1938, p. 147.

11 Ibidem, p. 151.

12 Thompson, 1930, p. 107. 
el que mejor explica los elementos simbólicos más importantes del vaso; los dos pájaros míticos, la cabeza humana que sostienen entre el personaje de elevada estatura y el tigre entronizado, la representación de esta última imagen mítica, los dioses descarnados sin mandíbula inferior y los numerosos símbolos de huesos que se repiten incesantemente en el atavio de las figuras humanas y en los dioses. Landa, cuenta sobre estas festividades lo siguiente:

...tomaban la imagen (de Ek u Uayeyab) en un palo que llamaban Yax ek y ponian a cuestas de la imagen una calavera y un hombre muerto, y encima un pájaro carnicero llamado Kuch, en señal de mortandad grande, pues por muy mal año tenían éste. Llevábanlo después de esta manera, con su sentimiento y devoción, y bailando algunos bailes entre los cuales bailaban uno, que le llamaban Xibalba opot, que quiere decir baile del demonio. Llegaban al camino los escanciadores con la bebida de los señores, la cual bebida llevaban al lugar de la estatua Uac Mitun Ahau, y ponianla allí frente a la imagen que traian.

Este año en que la letra era Cauac ... tenjan además de la pronosticada mortandad, por ruin, pues decian que los muchos soles les habian de matar los maizales, y las muchas hormigas y los pájaros comerse lo que sembrasen. ${ }^{13}$

Los mascarones descarnados y los huesos son símbolos que tienen relación con la tierra, con el inframundo donde se asientan los poderes tenebrosos, donde viven los dioses enemigos del hombre que buscan su destrucción o su desgracia. En el Popol Vuh, Xibalba es precisamente el nombre que tiene esta región y asf se llama el baile ritual en las festividades del año nuevo en el día Cauac. Una connotación semejante a la de Xibalba tiene el nombre de la estatua de Uac Mitun Ahau como señor del inframundo, de la región de los muertos.

Los pronósticos de destrucción de los campos de cultivo parecen indicar que las representaciones de Bolon Tz'acab en el vaso, muestran al dios de la lluvia en su aspecto maléfico, como deidad que colabora con el sol para "matar los maizales".

Los dos tigres cubiertos con una máscara sentados sobre la imagen de Bolon Tz'acab tienen relación también con la tierra. El tigre, según Thompson fue una deidad de la superficie de la tierra o de su interior. ${ }^{14}$ Landa relata que para remedio de los malos augurios que se pronosticaban para el año Cauac, los mayas de Yucatán hacian cuatro estatuas que llamaban Chic Chac Chob, Ek Balam Chac, Ah Conuol Cab y Ah Buluc Balam. Los nombres de dos de ellas tienen el elemento balam

13 Landa, 1938, p. 155.

14 Thompson, 1960, p. 12. 
que significa tigre. Tozzer dice que entre los mayas actuales existe la creencia de que un tigre guarda cuatro entradas a un pueblo orientadas, cada una, a los puntos cardinales. ${ }^{15}$

Los pájaros míticos, como el propio Landa lo explica, son aves maléficas, símbolos también de muerte y destrucción.

Los jeroglíficos del vaso no han sido interpretados aún, y no ayudan a aclarar el sentido que tiene la compleja decoración del vaso de Yalloch. No queda más que, por ahora, intentar aproximarse a su posible significado simbólico a través de lo que se sabe sobre las ceremonias religiosas de los mayas de Yucatán y lo que se conoce sobre el simbolismo de algunos de los elementos que aparecen en la plástica del periodo clásico maya. Lo que sí puede quedar asentada definitivamente es la gran calidad artística de esta hermosa pieza del arte cerámico maya.

\section{BIBLIOGRAFÍA}

ANDERs, Ferdinand. Das Pantheon der Maya. Grag, Austria, 1963.

GANN, W. F. Thomas. "The Maya Indians of Southern Yucatan and Northern British Honduras." Smithsonian Institute Bureau of American Ethnology. Bulletin 64. Washington, 1918.

Gordon, G. B. and Mason, J. A. Editors. "Examples of Maya Pottery in the Museum and other collections." University Museum. 2 Pts. Philadelphia, 1925-1943.

LANDA, Fray Diego de. Relación de las Cosas de Yucatán. 7a edición. Introducción y notas de Héctor Pérez Martínez. México, 1938.

Merwin, Raymond E. and Vaillant, George C. "The Ruins of Holmul, Guatemala." Peabody Museum. Memoirs 3, 2. Cambridge, 1932.

Proskouriaroff, Tatiana. "A Study of Classic Maya Sculpture." Publ. 593. Carnegie Institution of Washington. Washington, 1950.

Recinos, Adrian. Popol Vuh: Las antiguas historias del Quiché. Biblioteca Americana. Serie de Literatura Indígena. Traducción del texto original con una Introducción y notas. Fondo de Cultura Económica. México, 1953.

Roys, Ralph. The Book of Chilam Balam of Chumayel. University of Oklahoma Press, Norman, 1967.

Thompson, J. Eric. "Ethnology of the Mayas of Sothern and Central British Honduras." Field Museum of Natural History. Anthropological Series. Vol. xvis, núm. 2, Chicago, 1930.

Maya Hieroglyphic Writing. University of Oklahoma Press, Norman, 1960.

Tozzer, Alfred M. "Landa's Relacion de las Cosas de Yucatan." A Translation. Edited with notes by Alfred M. Tozzer. Papers of the Peabody Museum of American Archaeology and Ethnology. Harvard University. Vol. xvur. Cambridge, Mass., 1941.

15 Tozzer, 1941, p. 148, nota 728. 